\title{
Educação Ambiental Pós-Crítica como Possibilidade para Práticas Educativas Mais Sensíveis
}

\author{
Valéria Ghisloti Iared' \\ Lakshmi Juliane Vallim Hofstatter" \\ Ariane Di Tullio"'I \\ Haydée Torres de Oliveira ${ }^{\mathrm{I}}$
}

'Universidade Federal do Paraná (UFPR), Palotina/PR - Brasil "Instituto Federal de Educação, Ciência e Tecnologia Baiano (IF Baiano), Catu/BA - Brasil

'"'Fubá Educação Ambiental e Criatividade, São Carlos/SP - Brasil IVUniversidade Federal de São Carlos (UFSCar), São Carlos/SP - Brasil

RESUMO - Educação Ambiental Pós-Crítica como Possibilidade para Práticas Educativas Mais Sensíveis. O manuscrito apresenta contribuições da sensibilidade na criação de vínculos afetivos e engajamento nas temáticas ambientais. Os argumentos foram construídos a partir da análise de conteúdo de três pesquisas de doutorado, nas quais os resultados apresentaram dados que permitiram reflexões convergentes: I) vivências na natureza durante a infância, II) vivências e vinculações afetivas aos lugares e momentos, III) experiência estética/sensorial no meio ambiente. Concluímos argumentando pela relevância de uma virada ontológica na pesquisa e no aprofundamento de estudos que investiguem a interface entre as novas epistemologias ecológicas e a educação ambiental.

Palavras-chave: Virada Corporal. Fenomenologia-Hermenêutica. Educação Sensorial.

\begin{abstract}
Post-Critical Environmental Education as a Possibility for more Sensitive Educational Practices. This manuscript presents the contributions of sensibility in the creation of affective bonds and engagement in environmental issues. The arguments were built from the content analysis of three doctoral research studies in which the results presented data that allowed for convergent reflections: I- experiences in nature during childhood, II- experiences and affective bonds with places and moments III- aesthetic/sensory experience in the environment. We conclude by arguing for the relevance of an ontological turn in research and in the deepening of studies that investigate the interface between new ecological epistemologies and environmental education.

Keywords: Corporeal Turn. Phenomenology-Hermeneutics. Sensory Education.
\end{abstract}


Educação Ambiental Pós-Crítica como Possibilidade...

\section{Introdução}

Desde quando começou a surgir um campo de prática e pesquisa na educação ambiental em meados do século XX, algumas autoras e alguns autores se empenharam em traçar diferentes tipologias que remetiam a objetivos, enfoques e procedimentos específicos em relação à prática educativa.

Atualmente, são apresentadas e discutidas diferentes nomenclaturas que adjetivam a educação ambiental - educação ambiental crítica, ecopedagogia, educação ao ar livre - não sendo suficiente se restringir ao termo educação ambiental (Carvalho, 2004). Essas diferentes terminologias que aparecem na literatura internacional e nacional vêm sendo alvo de diversas pesquisas e debates (Reid; Scott, 2006; Robottom; Hart, 1993, entre outros). No entanto, tais classificações não são estáticas, e muitos ensaios argumentam que elas podem coexistir (Iared et al., 2011), dialogar (Layrargues, 2004; Payne, 2009) e, por que não, serem (re)significadas.

Destacamos que educadoras/es ambientais adotam posturas e posições bem diferenciadas dentro do campo da educação ambiental e acabam, muitas vezes, por se identificar e/ou posicionar dentro de alguma vertente específica. Essa variedade teórica e de práxis incentiva as pesquisas na área e dinamiza a busca pela compreensão do fenômeno relacional do ser humano com o ambiente com base em diferentes aportes teóricos, o que resulta também em um olhar mais atento sobre como está acontecendo a correlação entre a teoria e a prática ambiental educativa.

Desde a tese de doutorado de Arthur Lucas em 1972, existe uma diferenciação da educação ambiental em três abordagens: educação no, sobre e para o ambiente (Lucas, 1979). A educação sobre o meio ambiente objetiva o acesso à informação, enquanto a educação no meio ambiente é realizada nas áreas naturais, remete aos estudos do meio e à formação de vínculos afetivos, sendo mais guiada a emoções do que conhecimentos. A educação ambiental para o meio ambiente desenvolveu-se mais na década de 1990 com o crescimento da educação socialmente crítica, tendo como objetivo engajar pessoas e grupos em processos colaborativos, críticos e reflexivos, em situações práticas. Gough e Gough (2010) também relembram outras abordagens para a educação ambiental: Earth Education (Educação para a Terra), que, segundo eles, foi desenvolvida por Steve van Matre (1990) em contraposição à pedagogia crítica (critical pedagogy) de Paulo Freire (2011) ou propostas similares como teoria curricular crítica (critical curriculum theory) ou currículo socialmente crítico (socially critical curriculum).

A primeira abordagem se baseia na ecologia profunda, encorajando as/os educandas/os a construir um senso de relacionamento com o mundo natural, a interagir diretamente com os seres vivos ao seu redor e a compreender a complexidade da vida, mas rejeita perspectivas superficiais de um estudo do meio tradicional. A segunda abordagem questiona a perspectiva individualista da Educação para a Terra, sendo 
que, um currículo socialmente crítico enfatiza as práticas sociais individuais e coletivas, ou seja, o indivíduo é concebido como dentro da sociedade e é preparado para atuar (eco)politicamente.

Diante da constatação das diferentes posturas adotadas, Lucie Sauvé (2005), pesquisadora canadense, definiu 15 correntes da educação ambiental com base em uma análise dos bancos de dados ERIC e FRANCIS, o que se configurou como uma cartografia do contexto norte-americano e europeu. A própria autora demonstra a importância de incorporar os trabalhos da América Latina e outras regiões do mundo.

Da mesma maneira, Phillip Payne (2009), professor e pesquisador australiano, propôs enquadrar a pesquisa em educação ambiental com base no diálogo Norte-Sul, ou seja, respeitando as diferentes geoepistemologias (Canaparo, 2009) da educação ambiental. Esse conceito, proposto pelo professor argentino Claudio Canaparo (2009), refere-se a uma abordagem que busca compreender os espaços periféricos da cultura ocidental, em particular a América Latina. Já no cenário brasileiro, pontuamos o livro Identidades da Educação Ambiental Brasileira, publicado em 2004 (Layrargues, 2004), como um marco fundamental para contextualizar e enfrentar a “[...] babel das múltiplas educações ambientais” (Carvalho, 2004, p. 15).

Pesquisas desse cunho são importantes, já que os objetivos educacionais de nossas ações, projetos, programas na área ambiental revelam o que buscamos e que tipo de sociedade queremos. Sendo assim, encontramos na literatura nacional uma vasta quantidade de análises de pesquisas de mestrado e doutorado que identificaram as tendências e concepções de educação ambiental em livros didáticos escolares (Marpica, 2008), materiais audiovisuais (Silva, 2007), práticas docentes de professoras/es do ensino básico (Sguarezi, 2006; Souza, 2007), unidades de conservação (Valenti, 2010), programas de organizações não governamentais (Kogeyama, 2017), entre outros. Inclusive, temos hoje no Brasil um projeto sobre o Estado da Arte em Educação Ambiental (EArte), envolvendo três universidades (UNICAMP, USP e UNESP), o que consolidou um banco de dados da produção acadêmica em educação ambiental e em diversas pesquisas sobre as diferentes concepções, práticas, contextos e conteúdos do campo.

Geralmente, essas investigações formulam diferentes denominações de tendências em educação ambiental, como conservadora, romântica, reformista, emancipatória, transformadora, pragmática e crítica, que não são tão divergentes do primeiro modelo proposto por Lucas (1979), da educação no, sobre, para o ambiente, já explanado anteriormente. É importante destacar que, muitas vezes, as práticas em educação ambiental mesclam essas diferentes linhas/correntes epistemológicas, algumas vezes em uma escolha consciente, outras vezes por falta de um aprofundamento teórico e/ou mera reprodução de atividades já endereçadas à educação ambiental. Assim como as práticas são diversas, são diversos também os caminhos de formação de educadoras/es ambientais, que podem acontecer no ensino formal, não formal ou até informal, desde cursos de curta duração até intensas leituras em 
Educação Ambiental Pós-Crítica como Possibilidade...

pesquisa e prática docente, ou nos cursos de pós-graduação da área. Como esperado, isso resulta em diferentes escolhas, visões e práticas entre as correntes descritas.

Dessa forma, observamos, principalmente no cenário brasileiro, que acaba por existir uma tensão ou até mesmo uma cisão entre pessoas que se inserem em diferentes correntes educativas, principalmente nas que assumem a educação ambiental crítica. Isso porque existem muitas práticas e formações ingênuas ou mal endereçadas à educação ambiental, o que faz com que educadoras/es que aprofundam seus conhecimentos teóricos e buscam práticas mais orientadas sintam a necessidade de diferenciar essa condução de outras práticas que não almejam a transformação social pela via educativa e não são situadas politicamente.

Nesse sentido, o objetivo do presente artigo é apresentar e discutir a relevância da sensibilidade para a criação de vínculos afetivos e engajamento nas temáticas ambientais entre diferentes grupos de pessoas. Serviram, como base do presente manuscrito, os dados e as reflexões conjuntas de três pesquisa(dora)s de doutoramento, que aconteceram em diferentes contextos, porém, todas foram baseadas no paradigma interpretativo. A mútua inspiração dessas diferentes pesquisas, as trocas realizadas no grupo de pesquisa que as autoras partilhavam e a percepção da semelhança entre alguns dados gerados permitiram uma discussão convergente. Assim, pudemos refletir sobre a potencialidade da dimensão sensível nas atividades educativas no campo da educação ambiental, que tem por horizonte a construção de sociedades sustentáveis.

\section{A Dimensão Sensível na Educação Ambiental Pós-Crítica}

Com o passar dos anos, houve uma ampla apropriação do que se denomina educação ambiental crítica, acarretando novas discussões que buscam delimitá-la. Alguns educadoras/es defendiam que a educação ambiental crítica é aquela que segue os princípios marxistas e da escola de Frankfurt. Neste contexto, podemos citar o trabalho de Eunice Trein, de 2012, intitulado: Educação ambiental crítica: crítica de quê? Nele, a autora situou os referenciais marxistas que pautaram a análise crítica da sociedade, da apropriação material de grupos societários e exploração das forças de trabalho humano. A apresentação temática que a autora fez apontou as discussões sobre o tema supracitado e o contexto da inserção da educação ambiental no ensino formal e na formação de professoras/es, reconhecendo a ocorrência de práticas educativas que não contribuíam para romper os atuais modelos societários.

Não pretendemos explorar a fundo essas divergências da corrente crítica em relação às outras, pois, ademais a elas, pretendemos defender em nossa discussão um aspecto que consideramos importante: uma maior necessidade de trabalhar a dimensão sensível na educação ambiental. Nesse âmbito, consideramos educação ambiental pós-crítica aquela que motiva as capacidades criativas, reflexivas, corporais e 
a emergência da afetividade e do diálogo, afastando-se da percepção puramente racional e hegemônica dos dias atuais. É pós-crítica porque ao valorizar o sentir, o vínculo e a alteridade, amplia horizontes, nos remete a outras possibilidades de ser e estar no mundo com os não humanos em uma relação horizontal, ou seja, o que Sheets-Johnstone (2011) denominou como corporeal turn, traduzido como virada corporal. $\mathrm{O}$ autor argumentou contra um entendimento histórico de que o cérebro é superior aos demais órgãos ou ao conjunto do corpo. A virada corporal também é uma virada ontológica, pois traz outra compreensão ao negar a dualidade constituída em torno da razão/emoção ou hierarquia da mente em detrimento de todo o corpo. É uma perspectiva que traz para a análise a dimensão estética do corpo, enquanto experiência.

Hart (2005) argumentou que a reflexividade deve envolver a sensibilidade nas construções metodológicas das pesquisas em educação ambiental, direcionando para uma melhor resposta, consciência do processo e do seu posicionamento epistemológico, ontológico e político. Dessa forma, procuramos estabelecer um caminho de superação das ontologias duais ou estritamente focadas no ser para incorporar propostas que unificam o entendimento dos seres humanos, não humanos e mundo, denominadas como ontologia plana (Harman, 2005) ou ontologia simétrica (Steil; Carvalho, 2014).

A partir desse entendimento, as viradas afetivas (Clough; Halley, 2007), corporal (Sheets-Johnstone, 2011) e ontológica (Holbraad; Pedersen, 2017) são orientações filosóficas contemporâneas que questionam algumas dualidades decorrentes da visão antropocêntrica. Baseados nesses movimentos, Payne (2014) e Payne et al. (2018) apresentam evidências empíricas da não fragmentação entre estética ética política, ou seja, não há dissociação entre o corpo engajado e imerso no mundo e os posicionamentos diários (aqui entendidos como políticos). Steil e Carvalho (2014) usam o termo epistemologias ecológicas para se referir ao conjunto de atuações teóricas que visam o rompimento de dualidades.

A noção de estética referida nesse manuscrito é compreendida como propulsora de uma experiência sensorial e afetiva que é a base para interpretar nossas percepções e conexões com outros seres humanos e não humanos (Iared; Oliveira; Payne, 2016). Para Johnson (2007), historicamente, a dimensão da qualidade da experiência foi reduzida à superficialidade do julgamento subjetivo e juízo de valor, o que acarretou o seu esvaziamento e preconceito em relação a sua relevância no processo cognitivo. Da mesma maneira, Gadamer (2005) pontua que essa "[...] subjetivação da estética" acabou sendo compreendida como desvinculada da prática cotidiana e, muitas vezes, apenas relacionada ao campo da arte e à percepção do belo.

Muitos pensadores (Dewey, 1958; Johnson, 2007; Merleau-Ponty, 1999; Shusterman, 2008) ressignificaram o conceito de estética como a base da relação com o mundo, ou seja, é a conexão visceral com o mundo e intimamente ligada ao processo de atribuição de significado (em inglês, o meaning-making). Shusterman (2008) propõe o termo soma- 
Educação Ambiental Pós-Crítica como Possibilidade...

estético (em inglês, somaesthetics), definido pela atenção à experiência somática como elemento formador do processo cognitivo e, portanto, relacionado ao meaning-making.

Na educação ambiental, alguns trabalhos (por exemplo, Marin, 2007, Payne et al., 2018) argumentam sobre a relevância de trazer para o centro da discussão a educação que considere o sensível, já que a experiência estética suscita uma transcendência do olhar racional e imediatista da nossa compreensão como ser-no-mundo. Para além disso, a estética abre possibilidades para a imaginação, criatividade, afetividade e indagações acerca das posturas antropocêntricas da nossa sociedade.

Nessa perspectiva, há uma integração entre corpo, mente e cultura, na qual o corpo é concebido como um lugar sensorial de apreciação estética em um processo de conjunção e transição com a apreensão de sentidos. Johnson (2007) também é enfático ao afirmar que sua compreensão de atribuição de significado vai além dos pressupostos ou da formação de conceitos elaborados. O autor engloba os processos imaginativos, criativos, habilidades sensomotoras, afetos e emoções oriundos das experiências com/no mundo. Dessa maneira, a concepção de sensibilidade, no presente manuscrito, se refere aos encontros com as materialidades da natureza, tais como: vento; pedra; plantas; animais; mar; sol e outros não humanos - no qual há a abertura para a emersão de sentimentos, emoções, afetividades. Nosso aporte teórico se constitui de autoras/es que nos auxiliam a compreender melhor o afeto, o sensório, a corporeidade e a fusão entre os seres e o mundo.

\section{Pesquisas em Foco}

Na sequência, apresentaremos brevemente as três pesquisas de doutoramento cujos resultados subsidiaram as reflexões presentes neste artigo. Todas se pautaram no paradigma interpretativo, entretanto, cada uma apresentou questões de pesquisa e procedimentos metodológicos particulares dentro de seus contextos de estudo. Seus resultados permitiram uma reflexão convergente, que aponta para uma maior importância e valorização de espaços e de práticas educativas ambientais que promovam uma educação mais sensível.

\section{Pesquisa com Professoras do Ensino Básico}

A primeira pesquisa investigou o processo de formação e a criação das identidades de professoras do ensino básico como educadoras ambientais no contexto do Projeto ProMEA na Rede. Este foi desenvolvido entre 2011 e 2012 pela Prefeitura Municipal de São Carlos- SP, com o objetivo de institucionalizar as ações, projetos e programas de educação ambiental nas escolas municipais e, consequentemente, na sociedade sancarlense como um todo (Di Tullio, 2014). Para isso, foram selecionadas professoras do ensino infantil e fundamental que passaram a atuar como educadoras ambientais nas escolas em que lecionavam, no contraturno de trabalho. No presente artigo, o foco da análise dos 
dados recai sobre os aspectos sensíveis que contribuíram para essa formação na ótica das próprias professoras. Para identificar tais aspectos, revisitamos os dados anteriormente coletados por meio das técnicas de entrevistas e de grupos focais, escolhidas por possibilitarem o diálogo entre as professoras e delas com a pesquisadora.

\section{Pesquisa Sobre Valores no Cerrado}

A segunda pesquisa, desenvolvida entre os anos de 2011 e 2015, objetivou compreender a formação dos valores estéticos e éticos no bioma Cerrado (Iared, 2015). Na definição do público participante desse estudo, optamos por convidar grupos de pessoas que tinham um histórico de envolvimento afetivo em relação ao Cerrado, sendo que o perfil acadêmico foi um fator preponderante entre os que aceitaram colaborar com a pesquisa. A coleta de dados se deu por meio de duas técnicas: entrevistas semiestruturadas e caminhadas no Cerrado (walking ethnography). As caminhadas foram realizadas com os mesmos participantes das entrevistas, aproximadamente 18 meses após aplicação da mesma. A partir disso, foram elaboradas econarrativas (Payne, 2013) que buscaram descrever as respostas corporais e afetivas durante a experiência. Nesse estudo, vamos ressaltar a emergência das respostas afetivas, sensoriais e emotivas identificadas durante a coleta de dados.

\section{Pesquisa Sobre Relações Humanas com Áreas Verdes Urbanas}

A terceira pesquisa ocorreu na cidade Salvador entre 2014 e 2018 (Hofstatter, 2018) e trabalhou a importância das vivências ambientais urbanas, a criação de elos afetivos entre as pessoas e os lugares e o desdobramento do que foi vivido na infância, em relação à natureza, na constituição das pessoas adultas. Esta pesquisa objetivou compreender como se dá a relação humana com a biodiversidade no contexto urbano e quais são os caminhos percorridos e vividos por pessoas que possuem vínculos afetivos com a natureza urbana. A partir de uma aproximação da pesquisadora com um projeto de implantação de uma trilha no memorial da Mata Atlântica na Universidade Federal da Bahia-UFBA, iniciou-se uma formação de monitoras/es, estudantes de graduação para serem guias na trilha, que foram os sujeitos da pesquisa. A metodologia escolhida para a coleta de dados foi a walking interview, partir da gravação da entrevista e por narrativas feitas tanto pela pesquisadora, como pelas pessoas envolvidas. Essa é uma das formas possíveis de se trabalhar a walking ethnography. Foi solicitado que cada participante escolhesse um lugar com vínculo afetivo em Salvador, no qual ocorreu uma caminhada ou a realização de alguma atividade que apreciavam realizar ali, em uma perspectiva fenomenológica da vivência e constituição do ser a partir do contato com as áreas verdes urbanas. 
Educação Ambiental Pós-Crítica como Possibilidade...

\section{O Diálogo entre as Pesquisas}

Durante a revisão conjunta das três pesquisas, utilizamos a análise de conteúdo, aqui entendida como um conjunto de técnicas aplicadas para verificar e interpretar os registros das comunicações faladas ou escritas (Bardin, 2010). Para tanto, os dados utilizados foram aqueles que nos permitiram refletir, conjuntamente, sobre a importância do contato precoce e contínuo junto à natureza para a constituição de características sensíveis nos seres humanos. A partir dessa avaliação, foram construídas categorias emergentes, o que permitiu identificar as subjetividades manifestadas pelas participantes. Ressaltamos que esta envolveu um processo de interpretação das pesquisadoras dos documentos das três investigações. No entanto, dentro de cada investigação nos procedimentos metodológicos de cada tese, o processo de análise dos dados ocorreu conjuntamente com as pessoas participantes. De acordo com Gergen e Gergen (2006), a pesquisa qualitativa, em uma perspectiva pós-moderna, evidencia uma crise da representatividade, que considera muito limitante qualquer interpretação que se faça isoladamente, sem contexto ou participação da pessoa envolvida. Assim, além de considerarmos a perspectiva dos sujeitos de pesquisa, aceitamos que elas se plasmam às nossas próprias perspectivas e referenciais, e que nos imbricamos mutuamente tanto na realização da pesquisa como na análise e interpretação dos dados.

\section{Resultados e Discussão}

As três pesquisas foram colocadas em diálogo entre si e com a literatura, o que resultou nas seguintes categorias emergentes: I) vivências na natureza durante a infância, II) vivências e vinculações afetivas aos lugares e momentos, e III) experiência estética / sensorial no meio ambiente. Esses elementos se sobrepõem em vários apontamentos, pois estão associados, mas optamos por essa estruturação a fim de organizar com mais clareza a discussão dos dados. Para efeito de compreensão lógica, identificamos a qual pesquisa o excerto se refere, antecedido da forma com que o dado foi obtido.

I) Vivências na natureza durante a infância

Os resultados apontam para como a convivência com os demais elos da natureza é importante na formação de vínculos afetivos em ambientes urbanos, sendo que as vivências na natureza durante a infância foram um aspecto recorrente, como exemplificado pelos seguintes relatos:

Mas já minha infância, meu contato com a natureza foi brincar nesse bairro arborizado que foi sofrendo, foi passando pelo processo de urbanização desde pavimentação das vias que passou primeiro por paralelepípedo ou macaco, como alguns lugares chamavam. [...] E como foram sumindo as áreas verdes do bairro, inclusive, era motivo de conversa entre os irmãos (Entrevista, Pesquisa sobre valores no Cerrado). 
Os motivos que me levam a gostar desse lugar e de outras áreas verdes são os que me fazem relembrar de aspectos da minha primeira infância (Entrevista, Pesquisa sobre relações humanas com áreas verdes urbanas).

Percebemos a importância dos espaços verdes para o engajamento dessas pessoas no mundo e na forma com que cada uma se porta diante da vida. Algumas acreditam que o amor cultivado pela natureza influenciou a escolha profissional e o desejo de querer partilhar e ensinar sobre a natureza aos mais jovens ou de cuidar dos outros seres vivos, como destacamos:

Sempre que podia subia em um pé de árvore para admirar lá do alto todo o ambiente ao redor. Pode-se dizer que foi nesse período em que comecei a despertar para o cuidado com o meio ambiente, em especial os animais (Entrevista, Pesquisa sobre relações humanas com áreas verdes urbanas).

Estar ali reavivando memórias marcantes e o que me fez traçar o caminho profissional que escolhi para a minha vida. Percebi a trilha que percorri a partir de então, seja no ensino sobre a natureza ou no meu exercício como Bióloga (Entrevista, Pesquisa sobre relações humanas com áreas verdes urbanas).

Depois que eu entrei na Biologia, né? Porque assim, parece um certo compromisso. Se você é biólogo, você tem que respeitar a natureza. Pra mim é prazer, mas virou também meu local de trabalho (Entrevista, Pesquisa sobre valores no Cerrado).

Outros exemplos de falas apontam a importância da infância no estabelecimento dos valores e no modo de nos relacionarmos no mundo. Também se destaca a percepção do quanto a manutenção desses vínculos com o meio natural é vital para o equilíbrio emocional e para a paz interior, conforme os excertos:

Há muito mais em mim da natureza vivenciada na infância e juventude do que eu poderia imaginar (Narrativa, Pesquisa sobre relações humanas com áreas verdes urbanas).

Me fez refletir sobre o porquê de gostar tanto de estar 'no mato' e me fez reviver cenas e situações, que há muito não lembrava, da infância (Narrativa, Pesquisa sobre relações humanas com áreas verdes urbanas).

Assim, os resultados indicam que a infância exerce um papel fundamental na formação estética ética política das pessoas e, portanto, merece atenção nas práticas e pesquisa em educação ambiental. Payne (2018) advoga por uma necessidade vital de incorporar práticas ecofenomenológicas na educação ambiental de crianças. $\mathrm{O}$ autor argumenta sobre uma lacuna de estudos que se debruçam sobre as experiências estéticas das crianças na natureza com uma abordagem pós-crítica.

É interessante notar que nas três pesquisas, a escola não foi citada como referência para a formação dos valores éticos e estéticos com a natureza. Podemos considerar que grande parte das escolas se encerra em atividades constituídas exclusivamente dentro das salas de aula. E, conforme se observou, os vínculos afetivos se constroem com maior 
Educação Ambiental Pós-Crítica como Possibilidade...

efetividade nas vivências realizadas junto à natureza. Logo, precisamos pensar na ampliação dos espaços de formação e aprendizado formal, assim como discutido por McClaren (2009) e Russ e Krasny (2015).

Em um estudo com sete famílias, totalizando doze adultos e onze crianças com idade entre 8 e 16 anos, denominadas green families (famílias verdes, em português), Payne (2005) identificou a forte influência dos compromissos e interesses dos familiares com posicionamentos ecopolíticos na educação de crianças. Anteriormente a esse autor, mas em consonância com sua perspectiva, nas obras, $\grave{A}$ sombra desta mangueira e Pedagogia da Esperança, Freire (2010; 1994) menciona diversas passagens da sua vida e a relação com sua família e amigos, refletindo sobre a importância dessas vivências na construção da sua identidade e da sua leitura de mundo atual. Da mesma maneira, os resultados das três pesquisas destacam o papel da família e das vivências intergeracionais para a construção do vínculo afetivo e emocional sobre-no-para a natureza. Nesse sentido, argumentamos sobre a importância de maior integração entre escola, família e comunidade no sentido de trabalhar tais valores intencionalmente nos processos educativos.

O meu pai tinha um sítio incrível, que tinha uma cachoeira no fundo que a gente brincava lá, quase todo o dia nas férias, sabe? [...] Eu sempre prestei atenção nas árvores, nos animais, sempre gostei muito [...]. Eu gostava muito de animais, eu ajudava meu pai no sítio, dava vacina nos bois dele. Quando algum porco..., acontecia alguma coisa, se machucava, eu que ia lá ajudar, curar as bicheiras, as coisas, tudo, eu adorava (Entrevista, Pesquisa com professoras do ensino básico).

As professoras da primeira pesquisa não estabeleceram uma relação direta entre as suas vivências no meio ambiente durante a infância e/ou juventude e suas motivações para atuarem como educadoras ambientais nas escolas. No entanto, pesquisadores possuem opiniões controversas a esse respeito (Gough, 1999). Alguns defendem que é possível identificar que tipo de experiência pode produzir pessoas sensíveis e/ ou comprometidas com a questão ambiental (Palmer, 1998; Hsu, 2009), enquanto outros afirmam que as experiências relatadas não representam a realidade absoluta, mas são (re)interpretadas como significativas, à luz do momento presente (Chawla, 1998). Sendo assim, consideramos que as vivências no meio natural na infância e/ou juventude podem ter trazido contribuições importantes para a formação da sensibilidade ambiental das professoras, sem que haja uma relação direta entre elas, pois estaríamos subestimando a complexidade das experiências humanas ao longo da vida (Payne, 1999).

II) Vivências e vinculações afetivas aos lugares e momentos

A segunda e a terceira pesquisa levantaram alguns lugares nos quais as afetividades transbordam, como as áreas verdes urbanas ou áreas pouco antropizadas como zoológicos, áreas naturais, praças urbanas, chácaras, sítios, fazenda e casas na praia:

Quando criança, a lembrança... Em relação à natureza é mais voltado para as áreas assim... Parques, né? Âreas naturais. Mesmo morando em 
Iared; Hofstatter; Di Tullio; Oliveira

São Paulo minha infância inteira, a gente sempre procurava ir na Cantareira, ir em lugar, assim, mais voltado para essa área. Porque meu pai sempre gostou dessas coisas de madeira, árvore, então ele sempre levava a gente para conhecer esses parques (Entrevista, Pesquisa sobre valores no Cerrado).

Que uma coisa muito forte, demais da conta, é o mar que é uma coisa que, hoje em dia, está muito ausente. Mas crescendo no Rio de Janeiro, a praia era um ponto super presente na vida da gente, né? Todo fim de semana, todo feriado, as férias a gente tirava junto ao mar (Entrevista, Pesquisa sobre valores no Cerrado).

Relembramos histórias da infância, dos sabores das brincadeiras de criança nas praças, jardins e praia (Narrativa, Pesquisa sobre relações humanas com áreas verdes urbanas).

Viver a natureza, não só no Zoo, me faz sentir em paz (em casa). A energia presente nela, e toda a simplicidade que ela carrega, me faz dependente dessa tamanha lindeza (Narrativa, Pesquisa sobre relações humanas com áreas verdes urbanas).

A referência à infância e adolescência permanece presente nessa segunda categoria emergente. Para Tuan (2013), as categorias perceptivas do adulto são repletas de emoções que procedem das primeiras experiências na vida. Merleau-Ponty (1999, p. 24) considera que "[...] a criança compreende muito além do que sabe dizer, responde muito além do que poderia definir". Esses vínculos não podem ser criados se forem vividos de maneira esporádica, por isso a necessidade das áreas verdes no espaço urbano, onde a maioria das pessoas está vivendo (Oliveira, 2004).

Russ e Krasny (2015) argumentam sobre a necessidade da educação ambiental urbana tanto para o bem-estar humano, como para a integridade ambiental em cidades, considerando que as cidades são meios complexos onde os problemas socioambientais se concentram, ao mesmo tempo que geram oportunidades de reflexões, desenvolvimento de tecnologias e aprendizado. Alguns apontamentos das pesquisas permearam esse assunto:

E aí, o Cerrado aqui é uma realidade muito próxima porque tá, sei lá, 15 minutos da minha sala de aula. Dá pra você ir lá, ficar em silêncio. Parar um pouco a vida e olhar as coisas em volta (Entrevista, Pesquisa sobre valores no Cerrado).

Minha relação com a natureza foi construída, dentro dos aspectos de minha formação como pessoa, desde a infância com a colaboração de parentes, nos quais as áreas verdes urbanas, me marcaram pessoalmente (Narrativa, Pesquisa sobre relações humanas com áreas verdes urbanas).

Destacamos o papel da natureza no espaço urbano, pois é ela quem fornece esse contato mais cotidiano e acessível às pessoas que vivem na cidade. Além disso, ela também evoca a memória afetiva das pessoas ao revisitarem ruas, praças, árvores, parques em que cresceram e/ou tinham momentos prazerosos junto aos seus entes queridos.

Constatamos que a conexão com a natureza favorece a criação de um compromisso com o mundo. Assim sendo, afirmamos que diante da 
Educação Ambiental Pós-Crítica como Possibilidade...

importância das vivências ambientais na constituição dos seres humanos, não podemos deixar de refletir, enfrentar e (re)implantar mais vida nos espaços urbanos, recordando que grande parte das crianças hoje crescem nas cidades. Então, não podemos deixar de considerar a perspectiva apresentada por Payne et al. (2018), de que precisamos superar o ensino estritamente racional, investindo nas vivências enquanto forma de estabelecer vínculos e conhecimentos.

Na investigação do Cerrado, foram identificados como relevantes na formação da sensibilidade ambiental os momentos informais e espontâneos junto à família e amigas/os como o lazer coletivo - diversão, brincar, lúdico, estar com amigos e parentes; influência de pai/ mãe/ avô/ avó; férias/ finais de semana/ feriados. Esse aspecto também esteve presente na pesquisa sobre a formação de professoras ao observarmos que a família representa uma referência importante na formação dos valores éticos e estéticos, como podemos identificar nas falas seguintes:

Eu acredito que educação ambiental, amor à natureza, a preservação do planeta, tudo isso que a gente faz, a gente não nasce com isso. Eu acho que a gente aprende [...] vendo alguém trabalhar com muito carinho com isso, né, fazendo isso com muito carinho. [...] Meu pai sempre, ele pegava um punhadinho de terra e falava: 'quem tem um pouquinho de terra não passa fome'. Então, a questão do plantio: meu pai sempre plantou muito e eu cresci plantando (Entrevista, Pesquisa com professoras do ensino básico).

Então durante vários anos do período que eu atuo nessa escola, eu tentei trazer pra eles um pouco da minha realidade pessoal [...]. Então, eu tenho a horta que é uma coisa que vem de família... (Entrevista, Pesquisa com professoras do ensino básico).

Eu sempre prestei atenção nas árvores, nos animais, sempre gostei muito, mas era uma outra relação, eu tinha uma outra relação com o meio ambiente. Era aquela coisa do meu pai agricultor, de tirar pro sustento mesmo, explorar, não tinha essa coisa da preservação (Entrevista, Pesquisa com professoras do ensino básico).

Da mesma maneira que, no aspecto anterior, ressaltamos o papel das famílias - com o estudo de Payne (2005) - e a ausência da escola. O campo da educação ambiental no Brasil vem problematizando há décadas a lacuna no currículo escolar. Muitas pesquisas apontaram (e continuam apontando) a abordagem superficial e pontual da educação ambiental nas escolas. Nesse ponto, problematizamos o currículo engessado e descontextualizado, que não favorece a criação de vínculos com o local. Além disso, o próprio espaço físico escolar (com salas de aula, carteiras e corredores) não propiciam possibilidades para o corpomente sentir, saborear, ouvir, perceber e tocar.

Alguns autores argumentam sobre a (re)significação e (re)construção de valores de uma geração para outra a partir da reflexão e da interpretação das suas experiências (Dillon; Kelsey; Duque-Aristizabal, 1999; Payne, 2010). Essa perspectiva está de acordo com Gadamer (2005) que afirma que um sujeito não deixa seu próprio horizonte para se sub- 
meter ao horizonte do outro, mas ele o amplia para que possa integrar o outro, produzindo um novo conceito. Também podemos lembrar da educação da atenção, de Ingold (2010), que afirma que nenhuma pessoa é passiva diante de transmissão de saberes ou diante de um acumulado de representações. O autor argumenta sobre o papel das próprias experiências e da cognição em tempo real no processo de aprendizagem e formação do ser.

III) experiência estética / sensorial no meio ambiente.

Um aspecto da sensibilidade bastante presente nas falas anteriores é a experiência estética / sensorial no meio ambiente. Steil e Carvalho $(2014$, p. 164) afirmam que “[...] é impossível dissociar a mente do corpo, a cultura da natureza, o conhecimento da experiência. Para conhecer, a partir da perspectiva ecológica, é necessário estar imerso na matéria e no mundo através do engajamento contínuo no ambiente". Disso decorre que também devemos pensar em atividades educativas que potencializem o aprendizado corporal, pois pudemos perceber o quanto as vivências são importantes na criação de elos afetivos que impulsionam o desejo de cuidar e aprender:

Ah porque é bonito!!! [risos] porque é a vegetação que eu mais gosto [risos]. Porque eu adoro andar no Cerrado, eu adoro ver as cores do Cerrado, de sentir os cheiros do Cerrado. Então, é aquilo. Dispara os vínculos, os canais emocionais (Entrevista, Pesquisa sobre valores no Cerrado).

Muito, assim, dos cheiros, também, tem um cheiro diferente da cidade. Cheiro de mato. Á noite, o cheiro muda, eu acho. E você descobre coisas, aprende coisas (Entrevista, Pesquisa sobre valores no Cerrado).

E a gente chega, parece um abismo, cheio de verde, de Cerrado, de vida, umas rochas. Assim, eu fiquei duas horas sentada. Aí aquilo foi muito forte, mexeu muito comigo, eu falei 'isso aqui é muito bonito! É muito importante... sei lá, um monte de bicho mora aí, um monte de planta tá aí. Isso é muito importante porque olha o que eu tô sentindo agora olhando pra tudo isso!' (Entrevista, Pesquisa sobre valores no Cerrado).

Estar em contato íntimo com a natureza é ser natureza, não vendo mais como natureza externa, mas como nos mesmo. Íntima, transformadora e conectiva foi a conversa que tivemos naquele pôr do sol maravilhoso (Narrativa, Pesquisa sobre relações humanas com áreas verdes urbanas).

Segundo Grün (1994), historicamente, a escola tem valorizado apenas a dimensão cognitiva do processo de ensino-aprendizagem, desprezando sua dimensão axiológica. Isso não significa que essa instituição não tenha trazido ou não possa trazer contribuições para a criação de vínculos com o ambiente. No entanto, é preciso um planejamento e uma série de ações com intenção clara de refletir e (re)construir esses valores. A proposta de uma virada afetiva/ ontológica precisa ocupar o currículo, a formação de professores e a própria concepção do espaço construído, pois como afirma Steil e Carvalho (2014, p. 163), “[...] nosso modo de habitar o planeta não está separado do nosso modo de conhecê-lo". 
Educação Ambiental Pós-Crítica como Possibilidade...

Outro aspecto sensível identificado como relevante na vivência das professoras da primeira pesquisa foi a alegria e o prazer de trabalhar com a educação ambiental, bem como a satisfação proporcionada pelos resultados obtidos. A formação e a atuação das/dos educadoras/ es no cotidiano escolar são mais efetivas quando envolvem situações de prazer e alegria, o que possibilita a renovação dos sonhos e da esperança em transformar a escola e a sociedade, favorecendo mudanças nos valores e nas práticas profissionais e pessoais das/os educadoras/es:

Então, pra minha vida foi muito, muito gratificante, porque assim, quando você coloca a mão na massa, você se sente útil [...] quando eu fiz o trabalho dos pneus, do jardim de pneus, foi muito legal [...] foi gratificante, sabe, fazer isso pra escola. Sentir a escola mais harmonizada [...] fazer esse trabalho com as crianças me libertou (Entrevista, Pesquisa com professoras do ensino básico).

Porque é uma coisa que eu gosto e que eu sempre falei que trabalhar como educadora ambiental para mim era uma válvula de escape, era uma forma de sair da escola, sair desses problemas que vem da escola. [...] Então, era uma coisa que eu sempre gostei muito de fazer, então não era uma coisa que eu fazia por obrigação, eu fazia com gosto. Que era uma delícia! (Entrevista, Pesquisa com professoras do ensino básico).

Freitas (2004) se refere à alegria como um desafio à dimensão estética do processo educativo. Na fala da professora entrevistada, podemos perceber que o projeto trazia satisfação exatamente porque era uma possibilidade de sair da escola, ou seja, de modificar sua forma de atuação, pois as práticas escolares cotidianas não costumam gerar tal sentimento.

Na segunda pesquisa, durante a caminhada no Cerrado, a alegria aparece relacionada ao estar entre amigas/os naquele ambiente, o que se refletiu na interação, nas risadas, na descontração e relaxamento. As/ os participantes relataram no final da caminhada que haviam esquecido de que estavam participando de um momento de coleta de dados de uma investigação e questionaram se isso não poderia prejudicar a pesquisa. Além disso, sugeriram que atividades como essas deveriam ser realizadas com mais frequência, o que nos fez atentar sobre a relevância de incorporar intencionalmente essas práticas multissensoriais e informais no currículo da educação ambiental:

Para ela, estar entre amigos foi um prazer. [...] Ela manteve liderando um grupo de quatro pessoas, como se fosse a monitora, apontando alguns aspectos da visão que eram diferentes, como uma folha de veludo, muito comum no Cerrado. Muitas vezes, ela chamou as pessoas para ver outras frutas típicas, que não eram fáceis de comer uma vez que eles tinham uma casca rígida e grossa para quebrar (Narrativa, Pesquisa sobre valores no Cerrado).

Na pesquisa desenvolvida em Salvador, também se constatou a alegria de relembrar e fortalecer e querer oferecer às futuras gerações o que foi vivido junto à natureza: 
Recordar momentos felizes e de bastante aprendizado me fez querer (ainda mais) multiplicar esses sentimentos para as pessoas, principalmente às crianças e aos adolescentes, que são potenciais multiplicadores aqui, no presente e no inesperado futuro (Narrativa, Pesquisa sobre relações humanas com áreas verdes urbanas).

Nossos dados demonstram que o pensamento crítico e uma postura política podem ser construídos de diferentes formas. Por exemplo, o contato entre seres humanos com os demais elos da natureza pode criar vínculos profundos que geram o sentimento de defesa do meio ambiente, o que pode alavancar novos aprendizados das formas societárias de participação política e resolução de problemas. O que sinalizamos aqui é a potencialidade da dimensão sensível e da fenomenologia para além de uma inovação epistemológica da educação ambiental. Propomos uma virada afetiva e ontológica que revitalize e reorganize radicalmente nossos modos de pensar e fazer educação ambiental. Conforme explicitam Steil e Carvalho (2014), não se trata de designar uma unidade teórica, mas apresentar novos horizontes de compreensão para que se supere dualidades e o entendimento da natureza como algo alheio ou externo aos seres humanos.

Kincheloe e McLaren (2006) defendem a pesquisa pós-moderna crítica, pois percebem que as desigualdades sociais ainda precisam ser estudadas, debatidas e enfrentadas. Ressaltam, inclusive, que o capitalismo não pode ser naturalizado na sociedade e que devemos sempre questionar aquilo que parece óbvio. Entretanto, percebem um mundo em transformação e muito mais diverso e, nesse sentido, defendem uma maior abertura aos referenciais e metodologias da pesquisa crítica.

Defendemos, assim, uma ampliação de formas corporais de aprendizado, como a valorização dos aspectos sensíveis na constituição de seres humanos engajados para a emergência de uma educação ambiental pós-crítica. As vivências ambientais e práticas artísticas são ótimas oportunidades de trabalhar a multissensorialidade. Os humanos e muitos outros seres vivos se utilizam de todo o corpo enquanto forma de interlocução e expressão.

A informalidade dessas vivências na natureza é um aspecto relevante observado nos dados coletados, pois a partir delas são constituídos vários dos elos afetivos que trazemos vida afora, que se traduzem, também, no engajamento com e no mundo. Conforme Oliveira (2004, p. 25) a criança: “[...] necessita de espaço para conhecer o mundo, a natureza, exercitar seus movimentos, trabalhar seus sentidos, sentimentos e o tempo". Horton et al. (2014) realizaram um estudo sobre o cotidiano das caminhadas de crianças e jovens na Inglaterra e constataram o quanto essa mobilidade é importante na formação dos vínculos com a cidade, noções de espacialidade, no cultivo das relações de amizades (compartilhando histórias e brincadeiras) e identidade social e cultural, reafirmando mais uma vez o quanto os espaços e as vivências cotidianas na natureza são de extrema importância na constituição dos seres humanos. 
Educação Ambiental Pós-Crítica como Possibilidade...

Para tal, Carvalho e Mhule (2016) propõem uma educação ambiental fora da caixa, pautada na educação da atenção de Ingold (2010). As pesquisadoras relatam algumas situações de práticas educacionais que ignoram a experiência estética como pilar do processo cognitivo e esse rebaixamento pode indicar uma lacuna nas capacidades reflexivas, criativas e afetivas, competências necessárias para a educação de sujeitos autônomos e críticos.

A negação das atividades consideradas ingênuas na educação ambiental, como nos exemplos clássicos de abraçar as árvores ou fazer uma roda, recorre no perigo de afastar a educação ambiental das práticas mais corporais e afetivas, o apreender com o corpo e com as multissensorialidades, cada vez mais difundidos e discutidos na educação contemporânea (Iared; Oliveira, 2017). Não que essas práticas corporais sejam as únicas ou as ideais. Como qualquer outra atividade educativa e integrativa, elas precisam ser pensadas e problematizadas diante do contexto em que se trabalha, respeitando a abertura das/os educandas/ os ou construindo essa condição para que haja a entrega para o aprender e o experenciar com o corpo.

Nessaperspectiva, nãohá dissociação entre estética ética política durante as práticas corporais em educação ambiental. Na publicação Fields of Green, organizada por Marcia McKenzie, Paul Hart, Heesoon Bai, Bob Jickling em 2009, as/os autoras/es optaram por dividir os capítulos em quatro blocos, sendo um deles dedicado somente ao The sensuous (A sensibilidade, em português). Segundo elas/es, a educação ambiental tem a potencialidade de contribuir na superação da hegemonia do racional/conceptual e legitimar a inclusão das experiências emocionais e afetivas.

Pink (2009), por exemplo, argumenta sobre a indistinção da sensação e reflexão afirmando que a separação do corpo para o fazer e da mente para o conhecer implica na objetivação da experiência corporal pela racionalização. Além disso, Steil e Carvalho (2014, p. 163) expressam que o "[...] nosso modo de habitar o planeta não está separado do nosso modo de conhecê-lo”.

Para algumas/ns autoras/es (Fox; 2015; Gildersleeve, 2017; Lather; St. Pierre, 2013), a pesquisa nessa perspectiva se move do epistemológico para o ontológico, sendo nesse caso, um monismo ontológico, uma forma generalizada de holismo ou indicador de não antropocentrismo ou até, ecocentrismo. A concepção plana e não hierárquica de coisas, incluindo seres humanos, é de interesse educacional pós-crítico (Payne, 2016). Na mesma linha, Fay (1987) argumenta que a questão básica da ciência social crítica é sua ontologia e não sua epistemologia. Para o autor, existe um racionalismo excessivo arraigado e que se manifesta em ontologia de atividades:

[...] a fim de ter em conta essas dificuldades, mudanças profundas na concepção precisam ser introduzidas ao nível de seus pressupostos ontológicos. A ontologia da atividade precisa ser complementada com uma ontolo- 
gia de corporeidade, tradição, historicidade e imersão, e sua descrição da razão precisa ser modificada para refletir suas limitações inerentes, desvendar os mistérios da identidade humana e fazer as escolhas difíceis com o qual os seres humanos são inevitavelmente desafiados (Fay, 1987, p. 212, tradução nossa).

Acreditamos que os princípios e pressupostos da educação ambiental denominada como crítica podem recair em aspectos que precisam ser revistos, tais como a hierarquização e compartimentalização de saberes e o reforço de dualismos, tais como: razão x emoção; mente x corpo; ambiente x sociedade; afeto x política. Concordando com Latour (2013), precisamos reconhecer melhor os híbridos que nos constituem socialmente. Para o autor, não existe a purificação que separa a natureza da cultura, ou o mundo humano do não-humano. O autor defende que vivemos em um mundo em processo, em movimento, feito de presença e não permanência e afirma que "[...] o mundo dos sentidos e o mundo do ser são um único e mesmo mundo" (Latour, 2013, p. 127).

Um estudo recente que vem sendo conduzido por Alan Reid e Marcia McKenzie, intitulado Palgrave studies in education and the environment ${ }^{1}$, prevê a publicação de uma série de estudos teóricos e empíricos sobre a interface entre educação e ambiente. Na primeira publicação dessa série, os autores Jickling e Sterling (2017) editaram um livro com diferentes estudos que nos instigam a pensar no que vem sendo construído nessas últimas décadas sob a terminologia de educação para o desenvolvimento sustentável ou educação sustentável ou educação ambiental. Segundo os autores, "[...] tudo o que foi alcançado neste período, não é suficiente" (Jickling; Sterling, 2017, p. 02, tradução nossa) e defendem uma desconstrução para a reconstrução da educação ambiental que responda às crises ecológicas e aos imperativos educacionais atuais.

Em consonância com essa proposta supracitada, as discussões presentes nas três pesquisas nos fizeram refletir sobre a relevância de (re)pensar ou reenquadrar (Payne, 2009) ou descontruir para reconstruir (Jickling; Sterling, 2017) a educação ambiental pós-crítica. Portanto, faz-se necessário identificar as lacunas, reorganizar as concepções teóricas e os caminhos para o enfrentamento desses desafios.

\section{Considerações Finais}

Algumas identidades ou tendências educativas endereçadas como críticas estão sendo questionadas, por exemplo, por serem antropocêntricas e por aceitarem o dualismo cartesiano, separando mentecorpo e sociedade-ambiente. Existem educadoras/es que consideram como educação crítica aquela que promove uma reflexão e uma postura crítica no posicionamento cotidiano diante da vida. Mantém-se o entendimento da necessidade de que as práticas educativas tenham a potencialidade transformadora-emancipatória da sociedade, porém com maior flexibilidade em relação aos referenciais teóricos adotados 
Educação Ambiental Pós-Crítica como Possibilidade...

e às formas metodológicas de alcance desses resultados. Sinalizamos aqui que a contribuição da sensibilidade pode ir além de repensar os fundamentos epistemológicos. O sensível é potente para a emergência de uma educação ambiental pós-crítica e para a virada afetiva/corporal/ontológica.

Ao refletir sobre a frase histórica de Che Guevara, Hay que endurecerse pero sin perder la ternura, aplicada ao nosso contexto, sabemos que a educação ambiental crítica nos traz aspectos relevantes, nos quais temos que endurecer, pois não podemos deixar de travar lutas contra as injustiças sociais; contra governos autoritários e manipulativos; contra a apropriação de capital e dos recursos ambientais por grupos econômicos hegemônicos de poder; contra a fome; contra a degradação ambiental; pela saúde e pelo ensino público universal, por governos democráticos e participativos; por melhores condições de vida. Mas que haja a ternura das relações entre humanos e não humanos; da valorização do aprender com o corpo; com afeto; do olhar no olho; da conexão com a Terra; da contemplação; das brincadeiras de infância.

Ao colocar em análise as três pesquisas, o presente manuscrito objetivou relatar a contribuição do aspecto sensível para as práticas em educação ambiental. O argumento não tem o sentido de desvalorizar iniciativas que preconizem campanhas informativas ou o desenvolvimento de uma cidadania participativa e política, mas sim o de defender a incorporação de práticas educativas que contribuam para uma virada ontológica que conceba a indissociação entre estética ética política e uma relação sociedade-cultura-natureza menos antropocêntrica. Outras pesquisas devem ser incentivadas para investigar lacunas e possibilidades de (re)construção do currículo e práticas em educação ambiental que incorporem essas discussões, visando transformações soci ais ambientais afetivas éticas políticas mais significativas ${ }^{2}$.

Recebido em 22 de junho de 2020 Aprovado em 12 de abril de 2021

\section{Notas}

1 Em português: Palgrave Estudos em Educação e Meio Ambiente. Para maiores informações: <http://www.springer.com/series/15084>.

2 Educação \& Realidade informa que a publicação deste estudo foi em parte financiada pela Coordenação de Aperfeiçoamento de Pessoal de Nível Superior - Brasil (CAPES) - Código de Financiamento 001.

\section{Referências}

BARDIN, Laurence. Análise de Conteúdo. 4. ed. Lisboa: Edições70, 2010.

CANAPARO, Claudio. Geo-Epistemology: Latin America and the location of knowledge. New York: Peter Lang, 2009.

CARVALHO, Isabel Cristina Moura. Educação Ambiental Crítica: nomes e endereçamentos da educação. In: LAYRARGUES, Philippe Pomier (Org.). Identida- 
des da Educação Ambiental Brasileira. Brasília: MMA, Diretoria de Educação Ambiental, 2004. P. 13-24.

CARVALHO, Isabel Cristina Moura; MHULE, Rita Paradeda. Intenção e Atenção nos Processos de Aprendizagem: por uma educação ambiental 'fora da caixa'. Ambiente \& Educação, v. 21, n. 1, p. 26-40, 2016.

CHAWLA, Louise. Research Methods to Investigate Significant Life Experiences: review and recommendations. Environmental Education Research, v. 4, n. 4, p. 383-397, 1998.

CLOUGH, Patricia; HALLEY, Jean (Org.). The Affective Turn: theorizing the social. Durham: Duke University Press, 2007.

DEWEY, John. Art as Experience. New York: Minton Balch, 1958.

DI TULLIO, Ariane. Contribuições do Projeto ProMEA na Rede (São Carlos, SP) à Construção de Identidade e à Formação Ambiental Continuada de Professoras do Ensino Básico. 2014. 216 f. Tese (Doutorado em Ciências) - Centro de Ciências Biológicas e Saúde, Universidade Federal de São Carlos, São Carlos, 2014. Disponível em: <https://repositorio.ufscar.br/handle/ufscar/1819>.

DILLON, Justin; KELSEY, Elin; DUQUE-ARISTIZABAL, Ana Maria. Identity and Culture: theorizing emergent environmentalism. Environmental Education Research, v. 5, n. 4, p. 353-363, 1999.

FAY, Brian. Critical Social Science. Ithaca, NY: Cornell University Press, 1987.

FOX, Nick. Emotions, Affects and the Production of Social Life. British Journal of Sociology, v. 66, n. 2, p. 301-318, 2015.

FREIRE, Paulo. Pedagogia da Esperança: um reencontro com a pedagogia do oprimido. Rio de Janeiro: Paz e Terra, 1994.

FREIRE, Paulo. A Sombra desta Mangueira. 9.ed. São Paulo: Olho D’Água, 2010.

FREIRE, Paulo. Pedagogia do Oprimido. 50. ed. São Paulo: Paz e Terra, 2011.

FREITAS, Ana Lúcia Souza de. Pedagogia da Conscientização: um legado de Paulo Freire à formação de professores. 3. ed. Porto Alegre: Edipucrs, 2004.

GADAMER, Hans-Georg. Verdade e Método. Tradução de Flávio Paulo Meurer, 7.ed. Petrópolis, RJ: Vozes, 2005.

GERGEN, Mary; GERGEN, Kenneth. Investigação Qualitativa: tensões e transformações. In: DENZIN, Norman; LINCOLN, Yvonna. O Planejamento da Pesquisa Qualitativa: teorias e abordagens. 2. ed. Porto Alegre: Artmed, 2006. P. 367-388.

GILDERSLEEVE, Ryan Evely. Making and Becoming in the Undocumented Student Policy Regime: a post-qualitative [discourse] analysis of U.S. immigration and higher education policy. Education Policy Analysis Archives, v. 25, n. 31, p. 1-15, 2017.

GOUGH, Noel; GOUGH, Annette. Environmental Education. In: KRIDEL, Craig. (Org.). Encyclopedia of Curriculum Studies, v. 1. Thousand Oaks: Sage Publications, 2010. P. 339-343.

GOUGH, Stephen. Significant Life Experiences (SLE) Research: a view from somewhere. Environmental Education Research, v. 5, n. 4, p. 353-363, 1999.

GRÜN, Mauro. Uma Discussão Sobre Valores Éticos e Educação Ambiental. Educação \& Realidade, Porto Alegre, v. 19, n. 2, p. 171-195, jul./dez. 1994.

HARMAN, Graham. Guerrilla Metaphysics: phenomenology and the carpentry of things. Peru, Illinois: Open Court, 2005. 
HART, Paul. Transitions in Thought and Practice: links, divergences, and contradictions in post-critical inquiry. Environmental Education Research, v. 11, n. 4, p. 391-400, 2005

HOFSTATTER, Lakshmi Juliane Vallim. Biodiver-Cidade: vivendo e experimentando o espaço urbano na educação ambiental para e com a biodiversidade. 2018. 186 f. Tese (Doutorado em Ciências, área de concentração em Ecologia e Recursos Naturais), Universidade Federal de São Carlos, 2018.

HOLBRAAD, Martin; PEDERSEN, Morten Axel. The Ontological Turn: an anthropological exposition. Cambridge, UK: Cambridge University Press, 2017.

HORTON, John; CHRISTENSEN, Pia; KRAFTL, Peter; HADFIELD-HILL, Sophie. Walking ...Just Walking': how children and young people's everyday pedestrian practices matter. Social \& Cultural Geography, v. 15, n. 1, p. 94-115, 2014.

HSU, Shih-Jang. Significant Life Experiences Affect Environmental Action: a confirmation study in eastern Taiwan. Environmental Education Research, v. 15, n. 4, p. 497-517, 2009.

IARED, Valéria Ghisloti. A Experiência Estética no Cerrado Para a Formação de Valores Estéticos e Éticos na Educação Ambiental. 2015. 177 f. Tese (Doutorado em Ecologia e Recursos Naturais) - Universidade Federal de São Carlos, São Carlos, 2015. Disponível em: <https://repositorio.ufscar.br/handle/ufscar/7084>.

IARED, Valéria Ghisloti; OLIVEIRA, Haydée Torres de; PAYNE, Phillip. The Aesthetic Experience of Nature and Hermeneutic Phenomenology. The Journal of Environmental Education, v. 47, n. 03, p. 191-201, 2016.

IARED, Valéria Ghisloti; OLIVEIRA, Haydée Torres. Walking Ethnography for the Comprehension of Corporal and Multisensorial Interactions in Environmental Education. Ambiente \& Sociedade, v. 20, n. 03, p. 97-114, 2017.

IARED, Valéria Ghisloti; VALENTI, Mayla Walenti; MARPICA, Natalia Salan; LOGAREZZI, Amadeu José; OLIVEIRA, Haydée Torres de. Coexistência de Diferentes Tendências em Análises de Concepções de Educação Ambiental. Revista Eletrônica do Mestrado em Educação Ambiental, v. 27, p. 14-29, 2011

INGOLD, Timothy. Da Transmissão de Representação à Educação da Atenção. Educação, v. 33, n. 1, p. 6-25, 2010.

JICKLING, Robert; STERLING, Stephen (Org.). Post-Sustainability and Environmental Education: remaking education for the future. Palgrave Macmillan: Cham, 2017.

JOHNSON, Mark. The Meaning of the Body: aesthetics of human understanding. Chicago: University of Chicago, 2007.

KINCHELOE, Joe; MCLAREM, Peter. Repensando a Teoria Crítica e a Pesquisa Qualitativa. In: DENZIN, Norman; LINCOLN, Yvonna. O Planejamento da Pesquisa Qualitativa: teorias e abordagens. 2 ed. Porto Alegre: Artmed, 2006. P. 281-314.

KOGEYAMA, Cintia. As Diferentes Concepções de Educação Ambiental Presentes no Programa Nascentes Verdes Rios Vivos do Instituto de Pesquisas Ecológicas. 2018. 155 f. Dissertação (Mestrado) Escola de Artes, Ciências e Humanidades, Universidade de São Paulo, São Paulo, 2017.

LATHER, Patti; PIERRE, Elizabeth Adams. Post-Qualitative Research. International Journal of Qualitative Studies in Education, v. 26, p. 629-633, 2013.

LATOUR, Bruno. Jamais Fomos Modernos. 3 ed. São Paulo: Editora 34, 2013. 
LAYRARGUES, Philippe Pomier (Org.). Identidades da Educação Ambiental Brasileira. Brasília: MMA, Diretoria de Educação Ambiental, 2004.

LUCAS, Arthur. Environment and Environmental Education: conceptual issues and curriculum implications. Melbourne, Victoria: Australian International Press and Publications, 1979.

MARIN, Andreia Aparecida. Ética, Estética e Educação Ambiental. Revista de Educação PUC-Campinas, n. 22, p. 109-118, 2007.

MARPICA, Natalia Salan. As Questões em Livros Didáticos de Diferentes Disciplinas da Quinta-Série do Ensino Fundamental. 2008. 169 f. Dissertação (Mestrado), Centro de Educação e Ciências Humanas, Universidade Federal de São Carlos, São Carlos, 2008.

McCLAREN, Milton. The Place of the City in Environmental Education. In: McKENZIE, Marcia; HART, Paul; BAI, Heesoon; JICKLING, Bob (Org.). Fields of Green: restorying culture, environment, and education. Hampton Press, Inc, 2009. P. 301-306.

McKENZIE, Marcia; HART, Paul; BAI, Heesoon; JICKLING, Bob (Org.). Fields of Green: restorying culture, environment, and education. Hampton Press, Inc, 2009.

MERLEAU-PONTY, Maurice. Fenomenologia da Percepção. São Paulo: Martins Fontes, 1999.

OLIVEIRA, Claudia. O Ambiente Urbano e a Formação da Criança. São Paulo: Aleph, 2004.

PALMER, Joy. et al. An Overview of Significant Influences and Formative Experiences on the Development of Adults' Environmental Awareness in Nine Countries. Environmental Education Research, v. 4, n. 4, p. 445-464, 1998.

PAYNE, Phillip. The Significance of Experience in SLE Research. Environmental Education Research, v. 5, n. 4, p. 353-363, 1999.

PAYNE, Phillip. Families, Homes and Environmental Education. Australian Journal of Environmental Education, v. 21, p. 81-95, 2005.

PAYNE, Phillip. Framing Research: conceptualization, contextualization, representation and legitizimation. Pesquisa em Educação Ambiental, v. 4, n. 2, p. 49-77, 2009.

PAYNE, Phillip. Moral Spaces, the Struggle for an Intergenerational Environmental Ethics and the Social Ecology of Families: an 'other' form of environmental education. Environmental Education Research, v. 16, n. 2, p. 209-231, 2010.

PAYNE, Phillip. (Un)timely Ecophenomenological Framings of Environmental Education Research. In: STEVENSON, Robert; BRODY, Michael; DILLON, Justin; WALS, Arjen (Org.). International Handbook of Research on Environmental Education. New York, NY: Routledge, 2013. P. 424-437.

PAYNE, Phillip. Vagabonding Slowly: ecopedagogy, metaphors, figurations, and nomadic ethics. Canadian Journal of Environmental Education, v. 19, p. 47-69, 2014.

PAYNE, Phillip. What Next? Post-critical materialisms in environmental education. The Journal of Environmental Education, v. 47, n. 2, p. 169-178, 2016.

PAYNE, Phillip. Early Years Education in the Anthropocene: an ecophenomenology of children's experience. In: FLEER, Marilyn, van OERS Bert (Org.). In- 
Educação Ambiental Pós-Crítica como Possibilidade...

ternational Handbook of Early Childhood Education. Springer International Handbooks of Education. Springer: Dordrecht, 2018. P. 117-162.

PINK, Sarah. Doing Sensory Ethnography. London, UK: Sage, 2009.

REID, Alan; SCOTT, William. Researching Education and the Environment: retrospect and prospect. Environmental Education Research, v. 12, n. 3-4, p. 571-587, 2006.

ROBOTTOM, Ian; HART, Paul. Research in Environmental Education: engaging the debate. Geelong: Deakin University Press, 1993.

RUSS, Alex; KRASNY, Marianne. Urban Environmental Education Trends. In: RUSS, Alex (Org.). Urban Environmental Education. NY and Washington, DC: Ithaca, 2015. P. 12-25.

SAUVÉ, Lucie. Uma Cartografia das Correntes em Educação Ambiental. In: SATO, Michèle; CARVALHO, Isabel Cristina Moura (Org.). Educação Ambiental: pesquisa e desafios. Porto Alegre: Artmed, 2005. P. 17-46.

SGUAREZI, Nilza de Oliveira. A Formação de Professores em Serviço e as Possibilidades de Evolução das Concepções Naturalistas da Problemática Sócio-Ambiental e de sua Abordagem Educacional. Encontro de Pesquisa em Educação da Região Centro-Oeste, v. 1, p. 1-13, 2006.

SHEETS-JOHNSTONE, Maxine. The Corporeal Turn: Reflections on Awareness and Gnostic Tactility and Kinaesthesia. Journal of Consciousness Studies, v. 18, n. 7-8, 2011.

SHUSTERMAN, Richard. Body Consciousness: a philosophy of mindfulness and somaesthetics. Cambridge: Cambridge University Press, 2008.

SILVA, Rosana Louro Ferreira. O Meio Ambiente Por Trás da Tela: estudo das concepções de educação ambiental dos filmes da TV ESCOLA. 2007. 277 f. Tese (Doutorado) - Programa de Pós-Graduação em Educação, Universidade de São Paulo, São Paulo, 2007.

SOUZA, Alday de Oliveira. O Tema Transversal Meio Ambiente: o que pensam e como trabalham os professores da rede Estadual do Município de Vitória da Conquista. Práxis Educacional (online), v. 3, p. 245-262, 2007.

STEIL, Carlos Alberto; CARVALHO, Isabel Cristina Moura. Epistemologias Ecológicas: delimitando um conceito. Mana, v. 20, n. 1, p. 163-183, 2014.

TREIN, Eunice. A Educação Ambiental Crítica: crítica de que? Revista Contemporânea de Educação, v. 7, n. 14, dez. 2012.

TUAN, Yi-Fu. Espaço e Lugar: a perspectiva da experiência (trad. Lívia de Oliveira). Londrina: Eduel, 2013.

VALENTI, Mayla Walenti. Educação Ambiental e Biodiversidade em Unidades de Conservação: mapeando tendências. 2010. 99 f. Dissertação (Mestrado) - Programa de Pós-Graduação em Ecologia e Recursos Naturais, Universidade Federal de São Carlos, São Carlos, 2010.

VAN MATRE, Steve. Earth Education: a new beginning. Warrenville, Ill.: The Institute for Earth Education, 1990. 
Valéria Ghisloti Iared é Doutora em Ciências e Mestre em Ecologia e Recursos Naturais pela Universidade Federal de São Carlos. Bióloga pela Universidade Federal de São Carlos. Professora adjunta no Departamento de Biodiversidade, Universidade Federal do Paraná (UFPR), Grupo de Pesquisa em Educação Ambiental e Cultura da Sustentabilidade (UFPR).

ORCID: http://orcid.org/0000-0002-1082-9870

E-mail: valiared@yahoo.com.br

Lakshmi Juliane Vallim Hofstatter é Doutora em Ciências e Mestre em Ecologia e Recursos Naturais pela Universidade Federal de São Carlos. Bióloga pela Universidade Federal da Bahia. Docente no Instituto Federal de Educação, Ciência e Tecnologia Baiano, Campus Catu.

ORCID: http://orcid.org/0000-0002-6913-3499

E-mail: lakshmivallim@gmail.com

Ariane Di Tullio é Doutora em Ciências pelo Programa de Pós-Graduação em Ecologia e Recursos Naturais da UFSCar. Bióloga pela Universidade Federal de São Carlos. Co- fundadora, educadora e pesquisadora na Fubá Educação Ambiental e Criatividade.

ORCID: http://orcid.org/0000-0002-3463-8892

E-mail: ariane@fubaea.com.br

Haydée Torres de Oliveira é Professora Titular/Senior, Universidade Federal de São Carlos.

ORCID: http://orcid.org/0000-0002-9912-6230

E-mail: haydee.ufscar@gmail.com

Editora-responsável: Carla Karnoppi Vasques

Este é um artigo de acesso aberto distribuído sob os termos de uma Licença Creative Commons Atribuição 4.0 Internacional. Disponível em: <http:// creativecommons.org/licenses/by/4.0>. 